\title{
ETHICAL FASHION: SCALING FOR SOCIAL IMPACT - A PRESENTATION BY SAMANTHA JONES OF LITTLE YELLOW BIRD, THURSDAY 9 MAY 2019
}

\section{Katie Mangai}

Everyone in fashion wants to be sustainable these days. It seems to be de rigueur for fashion students to express a desire for their work, design and business practice to enter the marketplace clearly 'not guilty' of gross human rights abuses and environmental calamity. If this feels both obvious and optimistic, it still points to a reality where few would claim total ignorance of the issues at stake for the industry, even if many struggle to know how to act in response.

The 'why' of sustainable fashion is no longer big news. We know about Rana Plaza. We know 'fast fashion' is bad for both people and planet. And knowing this is (mostly) a good thing. But if the 'Why' has become obvious, the 'How' has a complexity that continues to simmer, begging resolution, long after the ease and rage of greenwashing activity and accusation ceases to function as click-bait. The 'How' is less glamorous and less righteous, but it is where the work has to be done, and is being done, by pioneers like Samantha Jones at Little Yellow Bird.

The Little Yellow Bird business model focuses on a core B2B offer of corporate uniform products (mainly shirts and aprons) which are also sold as wardrobe staples for the general public via the Little Yellow Bird website. Sales to the public currently account for approximately 15 percent of revenue, and this side of the business is set to grow. Samantha and her small team are based in a distribution warehouse in Wellington, with manufacturing taking place in various locations in India close to where their rain-fed organic cotton is sourced. HerWellington-based core team have roles that focus mainly on management and logistics, drawing heavily on a strong and trusted advisory group for assistance as needed, from design to finance and everything in-between. Samantha visits India regularly and from the LYB blog it is clear that out of the solid foundation of face-to-face relationships, along with a commitment to reflection and continuous improvement, community engagement initiatives have grown up alongside the production work in meaningful and impactful ways.

On Thursday 9 May 2019, local ethical textile waste pioneers Stitch Kitchen hosted a presentation by Samantha in the Otago Polytechnic Hub. Samantha had reached out to Stitch Kitchen, who in turn reached out to Otago Polytechnic, and from there the event was publicised through both Stitch Kitchen and the Design School's networks. In attendance were a mix of members of the public, Stitch Kitchen community, fashion and design students and faculty, and people connected to the Audacious business development programme. (A convergence that tells you something about the appeal of Little Yellow Bird and the importance of the way they are telling their story.)

Samantha's presentation was entitled "Scaling for Social Impact," and she talked through some of the Little Yellow Bird journey from start-up to this year's Pledge Me crowdfunding campaign.

The Little Yellow Bird Pledge Me campaign invites potential investors to "invest in ethical fashion" and "become part of NZ's first community-owned ethical fashion brand." Shares are being sold in order to scale growth and impact, 
and I left the event genuinely wanting to look further into the possibility of investing in this innovative enterprise. This is a great business lesson in itself - the storytelling matters! It was compelling, real, raw and very genuine. Samantha Jones very much wants to connect with like-minded individuals and share her knowledge.

The pursuit of whole supply-chain transparency in an apparel business is clearly not an easy road at any level, but Samantha is clearly a person of some tenacity. She comes to the apparel industry with military-trained supply chain expertise, and this military unflappability is clearly in evidence in the way she has gone after the core principles of her business. A huge focus has been building long-term relationships with her Orissa-based organic rain-fed cotton growers, visiting several times a year in the early stages of the business.

Little Yellow Bird came into being within the context of a Wellington-based business incubator, not dissimilar to Dunedin's own Audacious programme. Samantha opened her presentation with a quote from Reid Hoffman (the founder of Linkedln): "If you are not embarrassed by the first version of your product, you've launched too late." Some of what is interesting about Little Yellow Bird in the ethical fashion space is the extent to which it has benefited from business and social enterprise start-up advice and support.

Innovative business models are key to the thriving and surviving of any new fashion business, with or without an ethical focus, and while the industry has some unique challenges, aspiring sustainable fashion businesses would do well not to ignore the innovations and support of the wider business community. So much of the advice Samantha shared is just good solid business advice: Know why and how you are different from your competition, know when to give up and when not to, always be innovating, apply for everything and anything, engage in shameless selfpromotion, drive engagement, don't just do what has always been done, do what is right for you and your business. Be frugal. Get good advice.

Little Yellow Bird has done all these things and it has paid off. Their niche has been uniforms for hospitality and other corporate wear. The baristas in your favourite organic fair-trade coffee shop may be wearing organic fairtrade aprons and shirts thanks to Little Yellow Bird! You or I can also make individual purchases through their online platform and, as mentioned above, these sales currently make up around I 5 percent of their business.

The Little Yellow Bird model is certainly not the only approach to addressing issues of sustainability in the New Zealand fashion landscape, but when I reflect on similarities and differences between what is happening at Little Yellow Bird and established ethical labels such as Kowtow, or with Mindful Fashion New Zealand (brainchild of Kate Sylvester and Emily Miller-Sharma of Ruby), what I see is a landscape of diverse industry professionals, each working to their own strengths, in their own niche, with significant clarity of vision regarding what is in front of them. Gosia Piatek has built Kowtow, with its minimal, feminine and utilitarian aesthetic, to consistently produce garments which are highly sophisticated demonstrations of the way aesthetics and values and style can flow together. There is a clarity to the design that echoes the transparency in their supply chains, and a lack of fussy finishes sits well with ethical efficiency in production. For established New Zealand fashion designers, Mindful Fashion New Zealand sets out to solve some very practical issues in relation to auditing existing supply chains. Having had the opportunity to hear both Kate Sylvester and Emily Miller-Sharma talk about this initiative, I was equally impressed by how grounded that project is, focusing on what they can do right now, with the industry knowledge they have, to impact the supply chains they are already involved with that affect their everyday business. All of these approaches are encouraging.

The day after the Little Yellow Bird presentation I noticed on social media that a comment had appeared under a Little Yellow Bird promotion to the effect that if they really cared about sustainability they would use only hemp, and that the pledge was the work of more money-grabbing capitalists. Supporters jumped in to defend the brand, and Little Yellow Bird themselves replied promptly with appropriate clarity (incidentally, they are actually exploring adding hemp) - but the incident made me realise that in the real world of working it all out, for some nothing will be good enough. 
Little Yellow Bird is a business that thinks every decision through for its implications for sustainability, from working out ways to reduce the plastic used in export (tying garments in cotton instead of individually in plastic wrap) to marketing strategies that are specifically designed to reach consumers where the alternative is not non-consumption, but consumption of a less sustainable product. This is a subtle but significant endeavour that demonstrates some of the tensions present when growing an environmentally and socially sustainable business. Clearly greenwashing is a thing, but we can't give up the pursuit of genuine sustainability for fear of criticism, and we can't wait around until all the problems are solved before we even begin. I am looking forward to seeing what the future holds for Samantha Jones and Little Yellow Bird.

Katie Mangai is a student of fashion design at Otago Polytechnic. She holds an MA in applied theatre and a BA in theatre studies. After many years working on product development for a community investment consultancy, her interest in social justice and innovation in business (combined with a love of beautiful clothing) has led to a specific interest in sustainable fashion. 